\title{
Use of Constructivist Approach in Higher Education: An Instructors’ Observation
}

\author{
Irshad Hussain \\ Department of Education, The Islamia University of Bahawalpur, Bahawalpur, Pakistan \\ Email: irshad.hussain@iub.edu.pk, irshad_iub@yahoo.com
}

Received February $6^{\text {th }}$, 2012; revised March 11 ${ }^{\text {th }}, 2012$; accepted March 21 ${ }^{\text {st }}, 2012$

\begin{abstract}
The study aimed at exploring the significance of constructivist approach at higher education level. It also examined its effects on social learning of students. The researcher adopted observational method of descriptive research. The participants of the study consisted of students of Master of Arts in Education (M. A. Education) of the Islamia University of Bahawalpur. The researcher taught a course titled, "Qualitative research methods" for three years to three (different M. A. Education) classes. The researcher used constructivist approach and designed activities to involve students in the process of learning. The activities were offered to homogeneous (male-male and female-female) as well as heterogeneous (male-female) groups of students. On the basis of observation, the researcher concluded that students enjoyed working on collaborative and cooperative projects and tasks. They were keen on constructing knowledge by involving themselves in activities and showing their readiness to embrace constructivist approach. Constructivist approach played a significant role in the process of learning to constructing knowledge. Similarly, collaborative and cooperative work developed contribution spirit among students overcoming their shyness and introversion. They became independent and capable of taking initiatives in conducting research projects. They also learnt ethics, social skills and etiquettes in groups. However, some culture related problems like working of female students with their counterparts and shyness of rural students were noted.
\end{abstract}

Keywords: Constructivism; Knowledge Construction; Higher Education; Social Constructivism; Learning Activities; Productive Knowledge; Social Interactions

\section{Introduction}

\section{Higher Education: A Level of Knowledge Construction}

Higher education is considered to be the apex in all educational endeavors. It is imparted by universities and other institutions of higher education \& research. It embraces teaching and learning for the promotion of scholarship faculties and research attitude among students. It mainly focuses on knowledge creation and its dissemination. Apparently, teaching, learning and research are considered to be the core activities in higher education. Besides, there are some associated activities which seem to augment the outcomes and effectiveness of higher education. Such activities include instruction and instructional mechanism, learning activities, campus environment and infrastructure, innovations and interventions etc. (Hussain \& Reza, 2010).

According to Hussain \& Sultan (2010) university [higher] education aims at developing skills and competencies among students to live and work in $21^{\text {st }}$ century. Therefore, a university teacher should involve students in learning process through activities aiming to inculcate academic \& social skills among them. They would become capable of interpreting their knowledge according to situation(s) by making their own meaning of it. It would be broadening their vision and wisdom leading towards developing new knowledge.

\section{Constructivism: Construction of Knowledge}

The theory which emphasizes on providing opportunities to students for making their own judgments and interpretations of the situations (they come across) based on their prior knowledge and experience is called "constructivism". It is based on active involvement or participation of students in teaching learning process. It aims at developing skills among students by offering to them activities and projects in their relevant disciplines and contexts. It appears as an appropriate strategy preparing them for assuming social roles and professional responsibilities successfully in their practical lives ahead. According to Sobat (2003) construction of new knowledge is based on prior experiences of students by enhancing their rationality \& reasoning ability and applying in real situations.

Ismat (1998) stated that Piaget emphasized on individual constructivism associated with cognitive development and Vygotsky advocated for social constructivism. The former aimed at modifying beliefs and ideas of students by offering them appropriate tasks for knowledge construction; whereas, the later controlled to change their behaviors and cognition in social settings (Wang, 2003; Dhindsa \& Emran, 2006). Consequently, it contributes to social structuring of human cognition leading towards co-construction of knowledge (Simpson, 2002) through social interactions.

Hussain (1999) described learning as a social process taking place in and outside the classroom. Classrooms are social enti- 
ties where students interact with each other and their instructors (s) for learning to knowledge construction. There seems a consensus among different constructivists (like Dewey, 1916; Vygotsky, 1978; Bruner, 1996) that learners construct [their own] knowledge through social interactions with each other. In higher education, students are adults and they have prior knowledge and experience of life. They know the way to interact and live with others. They are believed to having the passion for group dynamics. Therefore, the assertion of Petraglia (1998) that instructors should develop learning materials and learning environment corresponding to the real world and/or situation of learners to interact accordingly seems appropriate for higher education classrooms. Hence, it necessitates the involvement of learners through activities for skill development and participation in life.

\section{Constructivism for University Students: Preparing Them to Participate in Life}

University students are assumed to be self-directed in their studies and activities provide them opportunities of hands-on practices for learning and interpreting it. They develop their own understanding of learning, its meaning according to the context, and the ways to acquiring it (Gibbs, 1992). They come with diverse potential, experience and mindset.

Therefore, Merriam (2001) viewed learners doing more than cognitive machines for processing information. They have their own mindset, memories, conscious and subconscious worlds, emotions, imagination and physical body which need to interact with new learning and learning contexts. Such learning contexts are social entities compelling the educationists to adopt constructivist approach at higher education level. The use of constructivism particularly, social constructivism (Vygotsky, 1978) develops confidence, respect for others, etiquettes and social skills among learners. They can interact with each other and exchange their pleasures and pains without hesitation. It may give them comfort and peace of mind for working more profoundly and earnestly.

\section{Review of Related Literature}

\section{Knowledge Construction through Constructivist Approach}

Constructivist approach corresponds to learning by doing assuming that the more repeatedly one does something, the more efficient $\mathrm{s} / \mathrm{he}$ become at it. It consists on different forms and activities including cooperative learning, experiential learning, problem-based learning and inquiry learning (Hussain \& Sultan, 2010). However, it is based on active involvement of learners and their interactions for creation of new knowledge.

Critical thinking, problem solving approach and analytical skills are assumed to be the essential constructs of higher education graduates. Equipped with such faculties and skills they construct new knowledge based on their previous experiences and involvement in learning process (Li, 2001). Similarly, Dhindsa, \& Emran, (2006) asserted that "knowledge is constructed through observation, reflection and interaction with the surrounding environment such as their peers, teachers or technology”. It is based on strategies of effective learning and leads them to construct new knowledge by interpreting it in a particular situation. In a constructivist classroom the teacher be- comes facilitator (Alesandrini \& Larson 2002; Ornstein \& Hunkins, 1998) to help students in acquiring knowledge through activities.

Students' involvement results in their effective learning. Johnson and Johnson (1999) stated that effective learning takes place through one's personal involvement in learning experience. It requires them to work in groups and interact in social settings based on the principle of Vygotsky's social constructivism. Vygotsky (1994) believed in social constructivism and asserted that social interaction among learners spurred the construction of new ideas and enhanced their intellectual development. Nonetheless to say that intellectual development and creation of ideas is associated with Bruners' (1960) pedagogies. Bruners' pedagogies included activity-based and hands-on instruction in which students were expected to use their own direct experiences and observations to acquire information and to solve problems scientifically.

\section{Role of Teacher in Constructivism: Teacher as an Academic Leader and Facilitator}

A teacher is considered to be the academic leader and facilitator of students. S/he recognizes their potential and helps them in right direction at right time. A constructivist approach is oriented on construction of knowledge putting students in practical situations under the guidance and tutelage of teachers. It seems to be based on the belief that learners construct their own knowledge through interaction, and the assumption that "knowledge is physically constructed by learners who are involved [actively in learning process]" (Gagnon \& Colley, 2001: p. 1) appears to be substantiating it. Knowledge is constructed in social environments where interaction is considered to be a fundamental factor for effective teaching learning process (Sims, Dobbs, \& Hand, 2001). Under such circumstances the role of a teacher cannot be neglected rather it becomes more significant in terms of coaching students to selecting appropriate activities for learning.

Traditionally, a teacher has been playing an active role in transferring knowledge to passive students. In new settings the stage is set for students to play an active role in learning process through activities. They feel pleasure and confidence in becoming active participant. The study of Lord, Travis, Magill \& King (2005) revealed greater effects of constructivist learning (learner-centered) approach on weekly test scores of students as compared to students' scores in traditional or teachercentered environment. The study further elaborated that constructivist learning helped them in enhancing their participation, level of satisfaction, enthusiasm for raising a question or responding to it, and an inclination towards scientific attitude. Constructivism makes teachers design activities and projects to be offered to the students. These may consist on service-learning and community-based projects and activities to involve students.

\section{Effects of Constructivism on Learning}

Use of constructivist approach in education has direct effects on students learning. They are active stake holders in the process of knowledge construction and its dissemination. They participate in teaching learning process and assume responsibility of their learning by giving it their own meaning in their respective contexts. Constructivism offers students opportunities of 
cooperative and collaborative learning.

A study was conducted by Santmire, Giraud, \& Grosskopf (1999) and compared learning achievement of two groups of elementary school students. The researchers found that the students who learned through social-constructivist approach to education and took a standardized test secured higher grades than their counterparts who were instructed traditionally in the classroom. The students' participation in such projects enhanced their academic performance as well.

Constructivism involves students and they participate actively in teaching learning process through different activities. Pratton \& Hales (1986) studied the influence of such participation of students on their learning achievement. The study found that the mean achievement of the students who participated actively in teaching learning process was greater than their counterparts who attended traditional classes. The study further explained that the students spent more time in doing activities that required thinking, responding and verifying their knowledge. Therefore, active participation of students (constructivism) was affirmed to be an efficient instructional approach for creating \& sustaining motivation and passion for knowledge construction.

\section{Rationale of the Study}

Hussain \& Mahmood (2010) stated that quality of education is directly linked with quality of instruction. Quality of instruction is associated with expertise and experience of teacher. An expert teacher adopts innovative instructional approaches. If such approaches are used at higher education level the students would become capable of developing new knowledge instead of mere getting information. Constructivist approach is one of them which aims at involving students in the process of learning. The researcher used it at higher education level and found encouraging results to be disseminated through this paper. This paper is an account of researchers' observation and reflects significance of using constructivist approach in higher education. This observational account of the researcher is given in the coming section of the paper.

\section{Objectives of the Study}

The main objectives of the study were:

- To evaluate readiness of university students towards constructivist approach.

- To study the significance of constructivist approach in higher education.

- To examine the effects of constructivist approach on social learning of university students.

\section{Procedure of the Study}

The study aimed at exploring the significance of constructivist approach at higher education level. It also examined its effects on social learning of students. The researcher adopted survey approach of descriptive research through observation. The participants of the study consisted on students of Master of Arts in Education (M. A. Education) of the Islamia University of Bahawalpur.

\section{Context of the Study}

This study explains researchers' reflection on the use of con- structivist approach at higher education level. The researcher taught a course on "qualitative research methods" by applying constructivist pedagogy. He taught it for three years to three different M. A. Education ( $4^{\text {th }}$ semester) classes at the Islamia University of Bahawalpur. The researcher designed activities on the principle of constructivist pedagogy and involved students in learning process. These activities were skill oriented and were offered to them in homogeneous (male-male and female-female) as well as heterogeneous (male-female) groups. The researcher observed and took notes of their readiness to participate in class activities, inclination towards group work; group dynamics and seriousness to cooperating and coordinating with each other for knowledge construction.

\section{Participants of the Study}

The total average number of participants of the study consisted on $32 \mathrm{M}$. A. Education ( $4^{\text {th }}$ semester) students of which eight (25\%) were males and 24 (75\%) were females. The researcher divided the participants into homogeneous as well as heterogeneous groups of 4 - 6 students each. Each group was similar in its physical characteristics and existed to work for a semester. The researcher noted his observation to know the significance of constructivist pedagogy at the end of each semester. However, he also recorded entry behavior of the participants at the beginning and terminal behavior at the end the semester and judged social competencies.

\section{Description of the Course}

The course, "Qualitative research methods” is a three credithour course offered in $4^{\text {th }}$ semester to the students of Master of Arts in Education. It is first course of its nature at masters' level and requires learners having some basic concepts of educational research as pre-requisite. It aims at equipping learners with knowledge of basic concepts and skills of qualitative research methods in education for making them capable of doing independent research projects, compiling, and disseminating their results appropriately. It also intends to develop social skills \& etiquettes, group dynamics, confidence, and writing and communication \& presentation skills among students.

In line with the objectives and intended learning outcomes, the course, consisted on basic concepts of "qualitative research methods" in education and activities for each of the methods. These contents of the course included procedure of conducting qualitative studies - observation, case study, interview, selecting population \& sampling, research tools \& their developments and administration, and working on independent research project. The instructor took a three-hour class weekly for 16 weeks.

\section{Students' Profile}

The participants of the study were 32 (25\% male and $75 \%$ female) students (average of the three classes) who completed their three semesters at the varsity. They had completed their 14-years education with majors in social sciences under annual system of examination. Now they were studying under semester system and having completed three semesters successfully in the varsity/co-education. They were aware of the university environment and appeared to be more confident than varsity 
beginners. Their academic record indicated consistency in achievement scores ranging from second to first division. They belonged to different social classes and geographical locationsurban and rural areas.

\section{Course Delivery or Instructional Mechanism}

The medium of instruction was Bi-lingual: English and Urdu. The researcher prepared brief handouts for students on each of the topics and delivered in advance to students for their study at home. They were also advised to consult books for further reading on qualitative research; like "Handbook of qualitative research" by Denzin, \& Lincoln, (1994) and "Doing qualitative research: Multiple strategies” by Crabtree, \& Miller (1992). The instructor explained concepts in classroom through multimedia presentations and invited queries from students. Discussion on different topics was also initiated to make students learn skills of behaving, arguing, acting and reacting in group(s).

At the beginning of the course, a copy of the course outlines and list of recommended books was provided to all students. A brief introduction of the course, its requirements and teaching learning strategies were also explained to the students. The researcher elaborated to students the significance of activities for substantiating their learning; "how to apply knowledge" instead of mere getting information. The instructor also tried to relate the research skills with professional and social life to motivate students intrinsically for their active involvement in learning process. All of the strategies for course offering were explained to the students. It helped the researcher make students' mind participate in learning process. In spite of all, the researcher practiced the principle of andragogical approach throughout the semester.

\section{Findings of the Study}

The researcher took notes of his observations on readiness of students to constructivism, its significance and effects on social learning of university students. The observation reflected remarkable findings which are given below:

\section{Readiness of Learners to Participate in Constructivist Activities}

The researcher designed activities to engage learners for developing skills of applying qualitative research methods in practical situations. It was observed that initially, they felt some difficulty to take initiative and work on assigned tasks. However, gradually they showed their keenness on taking academic initiatives in the class. They were feeling pleasure and enthusiasm by involving themselves in activities for constructing their own knowledge and applying it in their respective contexts. The researcher engaged them in working on case studies for profundity of knowledge. Case studies are assumed to be necessary for developing and enhancing cognitive skills of the learners.

They worked in groups voluntarily and showed inclination towards collaborative learning. The researcher assigned to them case studies on education to make them capable of applying their learning by evaluating and analyzing the situations. It would have been developing the power of judgment and critical analysis leading towards cognitive development and paving for advanced level of knowledge construction.
The researcher promoted collaborative learning by assigning them group tasks. The learners had distributed academic experiences and intellectual abilities, but actually, they were enjoying groups' dynamism for learning. They appeared to be cooperating with each other by sharing learning experiences, activities, and information. They were zealous in pooling academic resources for expanding their scholarship for learning. This practice appeared to be facilitating them in realizing learning for (knowledge) construction in adulthood.

The learners preferred to work on cooperative projects and therefore, were involved in such assignments for overcoming their shyness \& introversion. It extended opportunities of learning from each other by understanding the patterns of behaviors \& attitudes, thinking and inclination of fellows towards some specific as well as general academic topic or issue. It helped the diversified intellect come closer and accept diversity \& differences to live with.

\section{Significance of Constructivist Approach}

The learners were engaged in preparing a certain number of assignments for the entire course. It aimed at developing creativity and critical thinking: finding facts, and comparing \& contrasting them for value judgment. The researcher observed that learners presented materials in innovative styles and manners with some help. Gradually, the learner became capable of writing with flow, coherence, consistency, and uniformity after synthesizing the facts and information. They interpreted the information by going through instructional materials and tailoring the presentation of contents according to their respective learning styles.

It was observed that learners took part in discussions for sharing information or their view points about a topic/or concept and learning experiences for arriving at some sound and precise conclusions called new knowledge. Such discussions were initiated through seminars for elaboration of ideas and knowledge of the specific topic(s) or area(s) under debate. The learners participated in seminars eagerly to acquiring and sharing information about a burning issue or an important problem related to qualitative research.

The researcher noted that learners welcomed constructive feedback and encouraging comments on their assignments. They amended the weak parts of their assignments under the guidance of the researcher to meet the quality standards. Through practice under the guidance of researcher they could write abstracts and main points or summaries of the assignments and/or projects. They could report their observations of the field in the form of a comprehensive report with references. However, they needed mentoring and scaffolding in completing such tasks.

The researcher perceived that learning under constructivist approach students enjoyed academic autonomy-having benefits of the self-directed learning making them independent and self-decisive in their learning choices. The researcher reported that learners appreciated versatile and comprehensive group activities which empowered them by loosening their dependency on teachers and making them self-decisive and self-directed in learning choices. Likewise, it was witnessed by the researcher that female students persuaded more towards subject than their counterparts. However, male students appeared to be more submissive and cooperative with their fellows. 


\section{Effects of Constructivist Approach on Social Learning of University Students}

The researcher observed some effects of constructivist approach on social learning of students as reported below:

\section{Effects of Constructivist Approach on Social Learning and Etiquettes}

The researcher observed the effects of constructivist approach on learning etiquettes and mannerism of students. In the beginning of the semester low sociability of students was reported by the researcher. They showed shyness and introversion. They were reported to be feeling hesitation in working on collaborative and cooperative projects/tasks with their fellows of opposite gender. However, gradually collaborative and cooperative projects/tasks developed confidence among students. They learned to exchange morning greetings and pass smile. They learned the group dynamics and ethics of working on collaborative and cooperative projects/tasks. They facilitated each other in preparing assignments, presentations and other academic activities. At the end of the semester the researcher witnessed that majority of the students appeared to be out spoken practicing social skills and etiquettes. They showed caring attitude towards each other with patience and endurance for developing and maintaining academic relationships.

\section{Effects of Constructivist Approach on Personality Development}

It was observed by the researcher that academic collaboration and cooperation helped students to develop their personalities. It enhanced their communication skills to convey ideas and viewpoints appropriately. They became extrovert and expressive. They shared learning experiences with each other and sought help from teachers when needed. They desired to contribute to their learning community.

\section{Problems and Issues of Constructivist Approach}

The researcher observed to report some problems and issues in assigning collaborative and cooperative projects/tasks to students. Initially, some female students showed their reluctance to work with male students because of the social norm and values. Some female students observed veil and felt difficulty in working with male students. Similarly, some religious minded (male \& female) students had the same reluctance to work with their counterparts.

Similarly, the researcher noted some reluctance of girls coming from rural areas to work on collaborative and/or cooperative projects with male students. Likewise, the boys of rural socio-cultural background showed shyness, whereas their counterparts of urban culture sowed negligible or no hesitation to work with female students.

\section{Conclusion}

The researcher concluded that students enjoyed working on collaborative as well as cooperative projects and tasks. They were keen on constructing knowledge by involving themselves in activities and showing their readiness to embrace constructivist approach. Constructivist approach played a significant role in learning process to constructing knowledge. It helped them develop qualitative research skills and competencies. Similarly, collaborative and cooperative work developed contribution spirit among students overcoming their shyness and introversion. They became independent and capable of taking initiatives in conducting research projects. They also learnt ethics, social skills and etiquettes in groups. However, some culture related problems like working of female students with their counterparts and shyness of rural students were noted.

\section{REFERENCES}

Alesandrini, K., \& Larson, L. (2002). Teachers bridge to constructivism. Clearing-House. 75, 118-121. doi:10.1080/00098650209599249

Bruner, J. S. (1966). Toward a theory of instruction. Cambridge: Harvard University Press.

Bruner, J. S. (1996). The culture of education. Cambridge: Harvard University Press.

Bruner, J. (1960). The process of education. Cambridge, MA: Harvard University Press.

Crabtree, B. F., \& Miller, W. L. (1992). Doing qualitative research: multiple strategies. Thousand Oaks, CA: Sage Publications.

Dewey, J. (1916). Democracy and education. New York: The Free Press.

Denzin, N. K., \& Lincoln, Y. S. (1994). Handbook of qualitative research. Newbury Park, CA: Sage.

Gagnon, G. W., \& Colley, M. (2001). Constructivist learning design. URL (last checked 6 February 2012). http://www.prainbow.com/cld/clds.html

Gibbs, G. (1992). Improving the quality of student learning. Bristol: Technical and Educational Services Ltd.

Hussain, I., \& Sultan, S. (2010). Learning by doing: Outcomes of teaching a research course through group activities. Proceedings of the Annual International Conference on Computer Science Education: Innovation \& Technology (CSEIT) 2010, Singapore City: Global Science and Technology Forum, 6-7 December 2010.

Hussain, I., \& Mahmood, S. T. (2010). Practice teaching or internship: Professional development of prospective teachers through their pre-Service training programmes. Journal of Educational Research, 13, 105-122.

Hussain, I., \& Reza, A. (2010). Getting into varsity: A country case study of Pakistan. In B. Vlaardingerbroek, \& N. Taylor (Eds.), Getting Into Varsity—Comparability, Convergence and Congruence (pp. 117-126). Amherst, NY: Cambria Press Inc.

Hussain, I. (1999). A study of problems faced by distance education tutors in Bahawalpur Region. An un-published M.Phill thesis, Islamabad: Allama Iqbal Open University.

Ismat, A. H. (1998). Constructivism in teacher education: Considerations for those who would link practice to theory. ERIC Digest. URL (last checked 5 January 2012) http://www.eric.edu.gov

Johnson, D. W., \& Johnson, F. P. (1999). Joining together: Group theory and group skills (7th ed.). Englewood Cliffs, NJ: Prentice Hall.

Li, W. (2001). Constructivist learning systems: A new paradigm. International Conference on Advanced Learning Techniques, Madison, 6-8 August 2001.

Dhindsa, H. S., \& Emran, S. H. (2006). Use of the interactive whiteboard in constructivist teaching for higher student achievement. METSMaC 2006, 175-188.

Lord, T., Travis, S., Magill, B., \& King, L. (2005). Comparing student-centered and teacher-centered instruction in college biology labs. Indiana, PA: Indiana University of Pennsylvania

Merriam, S. B. (2001). Something old, something new: Adult learning theory for the twenty-first century. In S. B. Merriam, (Ed.), The New Update on adult learning theory, new directions in adult and continuing education No. 89, San Francisco: Jossey Bass.

Ornstein, A. C., \& Hunkins, F. P. (1998). Curriculum: Foundations, principles, and issues (3rd ed.). Needham Heights, MA: Allyn \& Bacon. 


\section{HUSSAIN}

Petraglia, J. (1998). The real world on a short leash: The (mis) application of constructivism to the design of educational technology. Educational Technology Research and Development, 46, 53-65. doi:10.1007/BF02299761

Pratton, J., \& Hales, L. W. (1986). The effects of active participation on student learning. Journal of Educational Research, 79, 210-215.

Santmire, T. E., Giraud, G., \& Grosskopf, K. (1999). An experimental test of a constructivist educational environment. Annual Meeting of the American Educational Research Association, Montreal, 19-23 April 1999.

Simpson, T. L. (2002). Dare I oppose constructivist theory? URL (last checked 5 January 2012). http://www.findarticles.com

Sims, R., Dobbs. G., \& Hand, T. (2001). Proactive evaluation: New perspectives for ensuring quality in online learning application. Con- ference proceedings of the 18th Annual Conference of the Australlian Society for Computers in Learning in Tertiary Education (ASCILITE), Meeting at the Crossroads, 509-517.

Sobat, T. (2003). Observations of constructivist teaching: A comparison of methods used in introductory and advanced instruction. Transactions of ID 705, 1, 1-8.

Vygotsky, L. S. (1994). The problem of environment. In R. van der Veer, \& J. Valsiner (Eds.), The vygotsky reader. Cambridge: Blackwell.

Vygotsky, L. S. (1978). Mind in society. Cambridge: Harvard University Press.

Wang, H. (2003). Vygotsky and his theory. URL (last checked 5 January 2012). http://www.ceo.ksu.edu/jecdol/vol3/ 